\title{
NOTICIAS SOBRE MORISCOS EN EL ARCHIVO MUNICIPAL DE VILLENA
}

\author{
Por \\ JOSE M. a SOLER GARCIA
}

El Symposium sobre moriscos celebrado en Alicante en mayo de 1980 , nos dio la oportunidad de reunir los datos acopiados en nuestras rebuscas por el archivo villenense, en el que tan extraordinaria labor de organización ha realizado nuestro buen amigo Antonio Cuéllar. Algunos de ellos vieron la luz en publicaciones de escasa difusión, y la edición de esta revista nos va a permitir darlos a conocer globalmente a los cada vez más numerosos interesados por estos temas.

En 11 de abril de 1369, don Juan Sánchez Manuel, conde de Carrión, y los procuradores villenenses Fernando Alvarez de Felguera y Domingo Busaldón, firmaron en Hellín unas capitulaciones para el reconocimiento de don Enrique de Trastámara y doña Juana Manuel como Reyes de Castilla, y entre otras cosas se decía: «Otrosy que perdonedes e fagades perdonar a los dichos señores todos e quales quier yerros que el dicho logar de Villena e los vezinos e moradores e abitadores della, assy christianos, judíos e moros, que ayan fecho e sean caydos en qual quier manera, assy del caso mayor fasta el menory. Se insiste luego en que se revoquen cualesquier gracias o mercedes que el Rey, la Reina o el infante "o otro qualquier que oviese logar o poder de lo fazer, de algunos bienes de algunos vezinos moradores del dicho logar de Villena, quier christianos, judíos o moros, que ayan fecho algunas personas». (Vid. «La Relación de Villena de 1575 », doc. XV).

El procurador Domingo Busaldón era jurado del concejo de Villena en 1372, e interviene de nuevo como procurador, en unión de Gonzalo García de Almodóvar, en el pleito-homenaje prestado en Almansa el 16 de marzo de 1386 sobre la sucesión en el Marquesado de Villena a la muerte de don Alfonso de Aragón (llbíd. doc. XXV), y es de señalar que en otro homenaje anterior a doña Blanca Manuel, celebrado en el Castillo de Garci Muñoz el 
25 de julio de 1351, figura como testigo otro individuo de la misma familia, Jaime Busaldón (Ibíd., doc. XIV). Hacemos hincapié en este apellido, que dio nombre a una plaza de la población y a una finca rústica que aún sigue denominándose «Usaldón», por su raíz indudablemente arábiga, puesta de manifiesto por GODOY ALCANTARA (Vid. «Ensayo histórico, etimológico, filológico sobre los apellidos castellanos», Madrid, 1871), que lo deriva, en su forma «Bujaldón», de Ebn Jaldón, nombre de un historiador de los berberiscos, «Algubet Borg Haldón», según un privilegio dado por Alfonso $X$ al concejo de Sevilla en 1253. Recordemos también al célebre historiador Aben Jaldún, que nació en Túnez de padres españoles en 1332. De ser esto así, vendría a confirmar que individuos de origen islámico, no sólo estaban avecindados en Villena en el siglo XIV, sino que ocupaban en ella los más altos cargos concejiles.

Para el siglo XV hay otra confirmación en el caso del moro Çahed Abdon Berberas, mercader de profesión, que, en 20 de diciembre de 1430 , obtuvo sentencia favorable de Pedro Jufre, teniente de Alcalde en Murcia, contra los recaudadores de aquella población, uno de cuyos procuradores se llamaba Mayr Aventuriel, quienes pretendían cobrarle almojarifazgo por las mercancías que allí compró y vendió. Su defensor, el procurador villenense Loys Sánchez de Arboleda, presentó la carta de vecindad del moro. En el proceso, que consta de diez y nueve folios, se insertan la exención de impuestos a los vecinos de Villena que establecían, tanto el Fuero de Lorca como los privilegios de Sancho IV, Enrique II, Juan I, Enrique III y Juan II.

\section{Asuntos de aguas}

Ha sido proverbial la riqueza de aguas subálveas de la comarca de Villena, de la que se han aprovechado casi todos los pueblos de las cuencas media y baja del Vinalopó.

Ya en 1270 , el infante don Manuel, por privilegio otorgado en Murcia el 4 de julio de aquel año, cedió a los pobladores de Elche el agua de Villena que pudieran llevarse, prometiendo ayudarles en la mitad del coste (Vid. CRISTOBAL SANZ, "Recopilación en que se da cuenta de las cosas ansí antiguas como modernas de la ínclita villa de Elche (1621)», Elche, 1954). Se habla también de un rescripto, fechado el 24 de agosto de 1392, por el que el rey Juan I de Aragón cede a los de Elda todas las aguas sobrantes de Villena. No nos ha sido posible comprobar este dato, pero sí existe una carta de don Juan Ruiz de Corella, fechada el 31 de julio de 1493, en la que le agradece al concejo de Villena el ofrecimiento del agua de la Fuente del Chopo y del Carrizo Blanco para sus vasallos, los moriscos del valle de Elda, que estaban en época de ayuno («La Relación....», doc. XCVIII).

Sobre este asunto de las aguas de Villena, que ha suscitado multitud de cuestiones con todos los pueblos interesados en su aprovechamiento, es muy instructivo el acuerdo del Cabildo celebrado el 2 de diciembre de 1624 que ofrecemos como documento IX. El número $X$ es la opinión del licenciado Ferrer, abogado de la ciudad de Murcia, que figura en el acta del día 22 de diciembre de aquel mismo año. 


\section{Noticias diversas}

En las cuentas de Propios y Rentas del año 1527, figura la siguiente partida: «Yten mandaron librar a Juan Galiziano, escriuano, trezientos maravedis de vn proçeso que hizo el alguazil mayor antel señor Governador contra çiertos moriscos de Gandia sobre çierto pan que dixo que hera perdido por sacarlo de aqui. Diose libramiento en forma en Pedro Díaz».

El documento I es una carta de don Juan Ruiz de Corella, conde de Cocentaina, en la que solicita de las autoridades villenenses la libertad de su vasallo Ali Moximi, preso en el camino de Caudete acusado de fraude.

Como documento II transcribimos una provisión del emperador don Carlos, expedida en Toledo el 27 de junio de 1529, sobre el uso de espadas $y$ puñales que el Alcalde Mayor y sus alguaciles impedian que llevaran los vecinos de Villena, en contra de uno de los acuerdos de las Cortes de Valladolid de 1520, que autorizaron llevar espada excepto a los nuevamente conversos del reino de Granada.

Interesante es la carta que dimos ya a conocer (Vid. «Las Relación....), doc. CXLVI), en la que don Francisco Maza da cuenta al Concejo de Villena de las gestiones que está llevando a cabo en la cuestión de los moriscos. Dado su interés, la transcribimos de nuevo como documento IV, rectificando el nombre del señor de Mogente, que no era don Pedro, sino don Francisco Maza. Existe otra provisión de Felipe II, fechada en Madrid el 23 de agosto de 1569 , en la que da licencia a los vecinos de Villena, que están en confín con muchos lugares de moriscos del reino de Valencia, para que puedan cazar con arcabuces, siempre que se guarden los meses de cría y las leyes que tratan de la conservación de la caza. La ofrecemos en nuestro documento $\mathrm{V}$.

En las cuentas que se tomaron al Mayordomo del Concejo, Bartolomé Calvache, en 27 de febrero de 1577, hay algunas partidas en relación con nuestro tema. Consta en una de ellas que se pagaron a Juan Jiménez, vecino de San Clemente, cuatro reales y medio por ciertos despachos del Gobernador para que no se diesen pasaportes a los moriscos de Granada. En otro de los motes se dice que «dio en descargo que pagó a Martín Ascar y otros tres compañeros vecinos de Monóvar, veinte y siete reales por razón de su trabajo, porque vinieron a esta ciudad a decir sus dichos en el pleito entre esta ciudad y la villa de Yecla sobre el pleito de la mojonera». La noticia en sí no tendría mayor importancia, pero la adquiere cuando comprobamos que el apellido Ascar corresponde a uno de los moriscos expulsados de Novelda en 1609, según la lista publicada por SALA CAÑELLAS («Crónica de la villa de Novelda», 1977), y adquiere todo su relieve al leer la partida final de las cuentas, en la que se justifica haber pagado a los testigos que vinieron de la villa de Monóvar a decir sus dichos sobre el pleito de Caudete, seis reales. Al final se nos aclara que se pagaron aquellos seis reales «a unos moriscos de Monóvar».

Curiosa e ilustrativa es también la noticia que leemos en el acta del 
Cabildo celebrado el 7 de junio de 1583, que dice textualmente: «Primeramente se leyo y notifico a los señores Alcaldes vn mandamiento en sus personas en que les manda tengan cuidado, que los moriscos del reino de Granada questan alistados no biban mas de vno en vna casa, ni hablen lengua araviga, ni otras cosas contenidas en el dicho mandamiento, los quales rrespondieron que en esta çiudad no (a) avido ni ai moriscos alistados, que por esta rrazon no ai para que hazer mas diligenciia sobrello, pero que si algunos vinieren, se guardara la forma y orden de su mandamiento».

\section{Expulsiones de moriscos anteriores a la de Felipe III}

La primera de que tenemos noticia es la de Jaime I tras la sublevación de los valencianos en 1257. Y nos afecta porque por Villena pasaron los que se dirigieron al reino de Murcia, a cada uno de los cuales cobró un besante el entonces gobernador de Villena don Fadrique, hermano de Alfonso el Sabio y del infante don Manuel, señor de Villena a la sazón.

La verdadera y casi definitiva expulsión se produjo tras la conquista del Marquesado de Villena por los Reyes Católicos, perfectamente estudiada por TORRES FONTES («La conquista del Marquesado de Villena en el reinado de los Reyes Católicos», Hispania, I, Madrid, 1953). No sería necesario insistir en ello si no hubiéramos encontrado una carta del procurador Diego Gasque al Emperador, sin fecha, pero perfectamente datable hacia 1531, que plantea interesantes problemas respecto a los bienes incautados a los conversos y cristianos nuevos cuando la villa se redujo a la Corona. La incluimos como documento III.

Algo de lo alegado por Diego Gasque parece haber sido intuido por los Reyes cuando aprobaron las capitulaciones entre los villenenses y el capitán Gaspar Fabra el 20 de febrero de 1476, que en uno de los capítulos decían lo siguiente: "Otrosy que los dichos Reyes nuestros señores non consentirán agora nin en ningún tienpo que sean tornados los dichos bienes a los dichos christianos nuevos, mas que sean de la villa como dicho es de suso. E que los dichos señores Reyes non consentiran agora nin por ningund tienpo que sean sacadas cartas algunas de escomunion nin de otra censura eclesiastica contra ninguna persona o personas que tomaron o tienen o se vsurparon los dichos bienes de los dichos xpianos nuevos nin contra el dicho Concejo, mas que si alguna carta o cartas fueren proveydas o sacadas por el Papa o por qual quier o qualesquier otros clerigos, que los dichos señores Reyes lo ayan de rremediar con los dichos perlados a sus propias costas o expensas» («La Relación...., doc. LXXVIII).

La expulsión de moriscos, judíos y cristianos nuevos fue total y tajante en 1476, y todavía durante los tres siglos siguientes, no hubo oficial del Concejo al que se le diese posesión sin haber probado antes su limpieza de sangre. El 7 de junio de 1583 se tomaron medidas contra alguna posible infiltración, como más arriba hemos señalado.

Pero los tiempos cambian, y con ellos las necesidades, y así vemos que el 18 de octubre de 1490 , en carta fechada en Córdoba, son los pro- 
pios Reyes Católicos los que toman bajo su amparo y seguro «a quales quier moros que a la dicha uilla de Villena se quisieran venir a beuir e a sus mugeres e fijos e bienes (...) («La Relación...», doc. XC), disposición que está en flagrante contradicción con la anteriormente comentada, y que puede estar en relación con el desmoronamiento del reino nazari y la necesidad de asentar a las familias granadinas huidas del desastre, porque de la misma fecha es otra disposición por la que se autoriza la erección en Villena de un barrio morisco de 150 casas.

\section{Proceso contra el alpargatero Juan Martínez y la cuestión de los sambenitos}

Capítulo aparte merece este proceso contra un alpargatero «que no era de casta de cristianos viejos», sin que se especifique si su naturaleza era mora o judía. Pensamos en la posibilidad de que fuera morisco porque, en el cabildo de 28 de julio de 1588 , se tomó el siguiente acuerdo: "que se apregone que todos los moriscos que traxeren a uender alpargatas a esta cibdad, antes e primeramente que las hechen a vender manifiesten las que trahen a Alonso de Gandía, alguazil, para que vea si son buenas y de ocho pasadas arriba, e no puedan vender en junto a ningún vezino ni forastero ni a tendero daqui a el jueves de mediodia abaxo auiendose hecho plaça, so pena de trezientos maravedis al que las vendiere y otros tantos al que las comprare, rrepartidos por terçeras partes, y que sean juezes los diputados y se apregone».

La ciudad se enfrentó abiertamente con los inquisidores en la cuestión de los sambenitos que hacían colocar en la iglesia de Santiago, porque, como muy bien se dice en el acuerdo de 18 de septiembre de 1580, «algunas personas que podrán tener en la dicha çibdad el mismo nombre se le podia seguir alguna nota de ynfamia». Efectivamente, en un alarde celebrado en 1582, se repite diez y siete veces el apellido Martínez, que es el segundo en frecuencia después del de Hernández. Se trata, por otra parte, de "uno de los apellidos de más abolengo en la población», al que dedicamos un apartado especial en nuestra «Relación...» (Nota n. ${ }^{\circ} 38$, pág. 149).

No podemos decir que tuvieran éxito las reclamaciones concejiles, porque los sambenitos siguieron colocándose en $1580,1581,1619 \mathrm{y}$ 1659 , contra judíos portugueses en esta última ocasiốn.

Toda la documentación referente a estos asuntos la hemos recogido en el documento n. ${ }^{\circ} \mathrm{XI}$.

\section{La expulsión de Felipe III}

Cuando en 1609 se decreta la expulsión, no queda en Villena ni un solo morisco. Así se desprende del cabildo celebrado el 24 de septiembre de aquel año y del acuerdo que puede leerse en nuestro documento $\mathrm{VI}$.

El 20 de noviembre del mismo año, se leyó una carta del Corregidor en la que transmitía la orden real de que se tuviera prevenida toda la gente 
que fuera posible por si hubiera necesidad de acudir «a apretar a los moros que el ejército del Tercio de Lombardía tenía cercados», según puede verse en el documento $\mathrm{V} / \mathrm{H}$.

El ciclo y nuestra aportación se cierran de momento, a la ęspera de nuevos hallazgos, con el acta de la sesión del 23 de agosto de 1614, que ofrecemos en el documento VIII, en la que el corregidor, don Antonio Alvarez de Bohórquez Girón, da cuenta de la carta de Felipe III en que se da por acabada la expulsión de los moriscos.

\section{Apéndice documental}

1493 - 3 de julio - Elda

Carta de don Juan Ruiz de Corella al Concejo de Villena en la que solicita la libertad de su vasallo Ali Moxini, preso en el camino de Caudete bajo pretexto de haber incurrido en cierto fraude.

Magnifichs e cars frares. Segons so informat que Ali Moxini, vassall meu de aquesta vila, venint de Caudet, en aquella lo haurieu pres aqui, pretenent seria caygut en cert frau. Yo en totes mes terres tracte los vassalls del S. R. ab tota cortesia, e senaladament los qui tich veyns axi com vosaltres, to que entre els altres haveu conegut per algunes speriencies. E segons tinch relacio, en lo loch hon lo han pres es cami de Caudet aci, e no seria inconvenient algu ell haver vengut per alli. E per co que demane de gracia deliureu lo dit Ali Moxini, e por ell e per tots los altres vassalls meu, feu lo que yo faria en son cars per vosaltres e per coses que tocassen al interes de aqueix vila. Offernitme prompte al que ordeneu. De Elda, a III de juliol, any Mil CCCC LXXX tres. A la hordinaçio de vosaltres prest com a frare. Corella, comte. (Rúbrica).

1529 - 27 de junio - Toledo

Provisión del emperador don Carlos para que todas las personas autorizadas a llevar espada puedan también llevar puñal, excepto los nuevamente conversos del reino de Granada.

Don Carlos, por la graçia de Dios Rey de romanos, Emperador senper augusto; doña Juana su madre y el mismo don Carlos, por la misma graçia Reyes de Castilla, de León, de Aragón, de las dos Seçilias, de Iherusalem, de Navarra, de Galizia, de Toledo, de Valençia, de Galizia, de Mallorcas, de Seuilla, de Córdova, de Murçia, de Jaén, de los Algarves, de Algezira, de Gibraltar e de las Yslas de Canarias e de las Yndias, Yslas e tierra firme del 
mar oçeano, Condes de Barçelona, Señores de Vizcaya e de Molina, Duques de Atenas e de Neopatria, Condes de Ruysellón e de Cerdania, Marqueses de Oristán e de Goziano, Archiduques de Avstria, Duques de Borgoña e de Bravante, Condes de Flandes e de Tyrol, etc. A vos, el que es o fuere nuestro Gobernador o juez de resydencia del Marquesado de Villena y a vuestro Alcalde, Alguaziles en el dicho ofiçio, e a vos, los Alcaldes e otres Justiçias quales quier de la çibdad de Villena e a cada vno e qual quier de vos a quien esta nuestra carta fuere mostrada o su traslado sygnado de escriuano público, salud e graçia. Sepades que las Cortes que tuvimos en la villa de Valladolid del año pasado de mill e quinientos e veynte años los procuradores de las çibdades e villas destos nuestros Reynos que por nuestro mandado se juntaron en las dichas Cortes, entre otras cosas que en ellas nos suplicaron pidieron por merced les mandásemos conçeder fue vn capitulo su thenor del qual y de lo que por nos a él fue rrespondido e avogado es este que se sigue. Otrosy, sabrá vuestra Alteza que sobre el traer de las armas e quitallas ay muy grandes debates y rrebueltas en las çibdades con los alguaziles, e justiçias, e porque vnos las quitan que no sería rrazón y a otros gelas dexan traer por dineros y otros coechos de malos alguaziles, y por esto porveyó vuestra Alteza que en la çibdad de Granada $y$ en la villa de Valladolid pudiese traer cada vno vna espada y que no se la quitasen, suplicamos a vuestra Alteza lo mandase asy proveer en todo el Reyno, no por que se quitaran grandes coechos e questiones e grandes ynconbenientes. A esto vos rrespondemos que cada vno pueda traer vna espada, açebto los nuevamente conversos del Reyno de Granada, con tanto que los que asy las truxieren no puedan traer aconpañamiento con armas de más de dos o tres personas, ni trayan las dichas armas en la mançebía, y que en la Corte no trayan ningunas armas onbres de pie ni moços despuelas como está mandado. E agora sabed que Juan Ruyz, en nonbre de la dicha çiudad de Villena nos hizo rrelaçión diziendo que como queyera que por el dicho capítulo de Cortes suso yncorporado y por la declaraçión por nos sobrello fecha está probeydo e mandado que cada vno pueda traer vna espada y vn puñal, diz que vos, el dicho Governador $y$ vuestro Alcalde mayor e alguaziles, yendo contra el tenor e forma dello, buscays e procurays formas y colores esquisitos para tomar las dichas espadas y puñales a los vezinos de la dicha çiudad e a las otras personas que a ella vienen haziendo hordenanças y pregones e vedamientos que ninguno traya las dichas armas ni las metan en las carniçería e percadería e mesones ni en la avdiençia e juzgado, sopena de perderlas, y de noche, de las nueve horas adelante diz que les tomays las dichas armas en qual quier lugar que las traen, e asy mismo diz que les tomays las dichas espadas hallándolas sin conteras, lo qual todo hera manera de coccho, y los vezínos de la dicha çibdad, resçibían en ello mucho agravio e daño, et nos suplicó e pidió por merçed en el dicho nonbre vos mandásemos que guardásedes el dicho capítulo de Cortes y la declaraçión dél, y dexásedes e consintiésedes traer libremente las dichas espadas y puñales a los vezinos e moradores de la dicha çiudad e a las personas que a ella vinieren, y que no gelas tomásedes avn questoviesen con ellas en la aviençia y carniçería 
e pescadería e mesones, ni so color que las traen syn contera, ni avn que las truxiesen después de las nueves o diez oras de la noche, pues por el dicho capítulo e declaraçión dél no está proybido, y mandásemos dar por ningunas las hordenanças, pregones y vedamientos que sobrello avíades fecho, o que sobrello proveyésemos como la nuestra merçed fuese. Lo qual visto por los del nuestro Consejo, fue acordado que devíamos mandar dar esta nuestra carta para vos en la dicha rrazón, e nos tovímoslo por bien, por que vos mandamos a todos e cada vno de vos segund dicho es, que veays el dicho capítulo de Cortes que suso va yncorporado e lo guardeys e cunplays segund e como en él se contiene, e por esta nuestra carta declaramos e mandamos que agora e de aquí adelante, todas las personas que por virtud del dicho capítulo pueden traer espada, puedan asymismo traer e trayan sy quisieren puñal juntamente con la dicha espada o syn ella, e mandamos a vos el dicho Governador y a vuestro alcalde e alguaziles e otras quales quier justiçias de la dicha çiudad de Villena, asy a los que agora soys e fuerdes de aquí adelante que dexeys e consyntays a los vezinos de la dicha çiudad traer las dichas armas e guardeys e cunplays e agays guardar e cunplir todo lo en esta nuestra carta contenido, segund e como de suso va dicho e declarado, syn enbargo de quales quier hordenanças e pregones e vedamientos que sobrello tengays fechos. E sy contra el tenor e forma desto averys tomado algunas armas e llevado algunos maravedís a los vezinos de la dicho çiudad, vos mandamos que gelas bolbays e rrestituyays e hagays bolber e rrestituyr luego libremente e syn costa alguna. E los vnos ni los otros non fagades ende al sopena de la nuestra merçed e de diez mill maravedís para la nuestra cámara. Dada en la çibdad de Toledo, a veynte y syete dias del mes de Junio año de mill e quinientos e veynte e nueve años. (Siguen cinco firmas).- Yo lohan de Bitoria, escriuano de cámara de sus cesáreas et católicas magestades. la fiz escreuir por su mandado con acuerdo de los del su Consejo.- Antón Gallo, chançeller.

Al pie: la carta acordada para traer espada y puñal a pidimiento de la çibdad de Villena.

III

Hacia 1531 - Villena?

Petición de Diego Gasque, en nombre del Concejo y vecinos de la ciudad de Villena, para que ni los Inquisidores ni el Juez de los bienes confiscados procedan contra los vezinos poseedores de bienes raíces que adquirieron de conversos y cristianos viejos cuando la villa se redujo a la Corona.

Muy poderosos señores: Diego Gasque, en nonbre del conçejo y vezinos de la çibdad de Villena digo que quando la dicha çibdad se rreduxo a vuestra corona rreal, los hijos de algo y cristianos viejos de la dicha çibdad 
tubieron sienpre la lealtad y fidilidad que heran obligados, dando la obidiençia y sujeçión a los señores Reyes Católicos, de gloriosa memoria. $Y$ los conbersos y cristianos nuebos vezinos de la dicha çibdad tubieron la opinión contraria, y entre los vnos y los otros, por la dicha cavsa y rrazón obo muy grandes diferençias e quistiones e muertes de honbres, hasta tanto que los dichos hijos dalgo y cristianos viejos, peleando con mucho ánimo, bencieron a los contrarios y los hecharon de la dicha çibdad, y rrecibieron en ella a mosén Gaspar Fabra, capitán de los señores Reyes Católicos, que en su nonbre tomó posesión de la dicha çibdad, e ansymismo se juntaron con el dicho capitán y cercaron la fortaleza y la tubieron çercada hasta que hecharon della a vn Pero Pacheco, alcalde del duque de Escalo$n a, y$ a los que con él estaban, y en alguna rremuneraçión de los dichos serbiçios tan señalados, los dichos señores Reyes Católicos hizieron merçed a los dichos hijos dalgo y cristianos viejos de todos los vienes muebles y se mobientes que obiesen tomado a los dichos conbersos y cristianos nuevos en la dicha guerra y pelea, e asy mismo mandaron que el dicho capitán Gaspar Fabra, en nonbre de sus Altezas, diese o bendiese los vienes rraízes de los dichos conbersos y dispusyese de ellos a su boluntad, e asy el dicho capitán los bendió e hizo dellos lo que le paresçió que conbenía al serbiçio de sus Altezas, y las personas vezinos de la dicha çibdad que obieron los dichos vienes rraízes por bía de conpra o por otro título y sus suçesores los han tenido y poseydo libremente más ha de çincuenta $\mathrm{e}$ çinco años, $y$ ansy es que como después los dichos señores Reyes probeyeron santamente que obiese ynquisiçión en estos rreynos, los ynquisidores del partido de Murçia, de poco tienpo a esta parte, an proçedido contra algunos de los dichos conbersos y confiscados sus vienes, y por cavsa de la dicha confiscaçión, el juez de los vienes confiscados del dicho partido proçede contra los vezinos de la dicha çibdad posedores de los dichos vienes rrayzes, en lo qual rreçiben mucho agrabio y daño, porque abiéndose vna bez perdido como se perdieron todos los vienes de los dichos conbersos y cristianos nuebos y aplicádos a vuestra cámara e fisco por cavsa de la dicha rrebelión, y tiniendo como tienen título de Vuestra Alteza los posedores dellos, avnque los dichos conbersos ubieran antes cometido los delictos de herexía por que fueron después condenados y confiscados sus vienes, no pueden ni deben ser molestados los vezinos de la dicha çibdad posedores dellos, pues que tienen y poseen los dichos vienes como cosa que pertenesçió a vuestra cámara e fisco y por título y conçesión de los dichos señores Reyes Católicos, porque conforme a derecho, aquellos mismos vienes no pudieron ser más de vna bez de vuestra cámara o fisco, avnque obiese derecho para ello por muchas cavsas, y pruébase bastante mente ser esto ansy por el tenor del previlegio que entonçes se conçedió a la dicha çibdad e vezinos della, el qual asentó original mente donde paresçe que sus Altezas hizieron merçed de los dichos vienes muebles y semobientes, y por consyguiente es cosa muy cierta que mandarían disponer de los vienes rraízes como cosa perteneçiente a su cámara y fisco. Por ende, pido e suplico a Vuestra Alteza mande a los dichos ynquisydores y al Juez de los vienes confiscados del dicho partido de 
Murçia que no proçedan contra los vezinos dela dicha çibdad posedores delos dichos vienes rrayzes, o que a lo menos Vuestra Álteza mande que se sobresea en la proseçución de los dichos pleitos y que estén en el estado que agora están, porque paresçiendo como pareçerá ser verdad lo que dicho tengo, no es justo que los vezinos de la dicha çibdad sean fatigados y molestados sobre lo que tan justamente tienen y poseen, en lo cual Vuestra Alteza administrará justicia y hará a la dicha çibdad e vezinos della mucho bien e merçed. (Rúbrica)

En las espaldas: «La villa de Villena».- "Texeda».- V.- "Que el fiscal lo vea y faga rrealaçión dello.- «A los inquisydores que sy les mostraren merced de sus altezas que tienen de bienes rrayzes y lo fagan guardar».

\section{IV}

1542 - 14 de mayo - Mogente

Carta de don Francisco Maza al Concejo de Villena dándole cuenta de las gestiones que está llevando a cabo en la cuestión de los moriscos.

Nobles señores: de la yda de don Joan mi hijo a entender y castigar los que se hallaren culpables destas muertes que se hizieron en el Pinoso, no melo deveys agradecer, pues hago lo que devo, y ahun quisiera hazer mas si mas pudiesse, y ansi haveys de ser ciertos que todo lo que tocare a mi jurisdiction conforme a josticia, no dexare de hazer lo devido. En Polop, ni yo tengo jurisdiction ni su duenyo creo que la tiene, que si la tuviesse don Alonso Fajardo, que es señor de aquel lugar, muy cierto estoy yo que la haria por amor de vosotros y de mi, pero los moros de la mar, segun he oydo dezir, mandan alli mas que el; yo scrivire a don Gaspar Sans, si'sta en Benidorm, y creo que es arrendador de alli, y si el lo puede hazer lo hara porque es mi amigo, pero tiene poca gente en Benidorm para sojusgar aquellos moros, y tantbien scrivire al Gobernador de Xativa, que esta en su jurisdiction, pero ya sabeys como sta aquella tierra. Todo lo que conoscays en este caso que sea justo y yo pueda hazer scrivimelo, que yo lo hare; digolo para los lugares estrayos, que para los mios, don Joan ha embiado a mosen Jaume Dezpuig por el morisco qu'esta en Elig, y yo le he escrito tantbien a Joan Vacca, y ansi mismo he scrito al procurador d'Elda diesse la morisca muger de Ffaratget, qu'esta pressa en Elda; si lo hazen, con ellos y con los que tengo pressos y otros si en mis tierras estuvieren, se hara lo que fuere josticia, que don Johan ha embiado ya por micer Terres a Orihuela, por que sin letrado no se puede entender en lo que se ha de hazer. Sto es lo que puedo atta agora dezir. Guarde N. S. vuestras nobles personas. De Moxen, a XIIII de mayo de MDXXXXII. A lo que mandeys. Don O maça de 


\section{V}

1569 - 23 de agosto - Madrid

Provisión de Felipe II por la que da licencia a la ciudad de ViIlena para que los vecinos de ella, de su tierra y de su jurisdicción, que están en frontera y confín y parten términos con muchos lugares de moriscos del reino de Valencia, puedan tener y tirar con arcabuces, siempre que no sea con perdigones y se guarden los meses de cría y las leyes de conservación de la caza.

Don Felipe, por la graçia de Dios Rey de Castilla, de León, de Aragón, de las dos Seçilias, de Jerusalem, de Nauarra, de Granada, de Toledo, de Valencia, de Galizia, de Mallorca, de Seuilla, de Cerdena, de Córdoua, de Córcega, de Murçia, de Jaén, Conde de Flandes y de Tirol, etc. Por quanto por parte de vos, el Conçejo, Justiçia y Regimiento de la çiudad de Villena nos fue fecha rrelaçion diziendo que essa çiudad estaua en frontera y confinaba y partía términos con muchos lugares de moriscos del rreyno de Valençia, a cuya causa los vezinos della biuían con reçelo, espeçialmente por estar desaperçebida de arcabuzes, y los pocos que abía, las justiçias los mandauan quitar y quitaban a las personas que los tenían, de lo qual resçiuían agrauio, y nos suplicó les mandássemos dar liçencia y facultad para tener los dichos arcabuzes en sus casas y tirar con ellos a qualquiera caça, sin que por ello fuessen bexados y molestados, o como la nuestra merçed fuese. Lo qual visto por los del nuestro Consejo, fue mandado que deuíamos mandar dar esta nuestra carta para vos en la dicha razón, y nos tubímoslo por bien, y por la presente damos licencia y facultad a los vezinos dessa dicha çiudad y su tierra y jurisdiçión para que pueda tener en sus casas los dichos arcabuces y los sacar al campo y tirar con ellos a la dicha caça, con que no sea con perdigones y guardando los meses de la cría y leies de nuestros rreynos que disponen cerca de la conseruaçión de la dicha caça, sin que por ello caygan ni yncurran en pena alguna. Y mandamos a quales quier jjstiçias dessa dicha çiudad y sus tierras y jurisdiçión que sobre ello no los prendan ni moleste ni les hagan otro agrauio alguno de que tengan causa ni rrazón de se nos venir ni ynbiar a quexar sobre ello. De to qual mandamos dar y dimos esta nuestra carta, sellada con nuestro sello y librada de los del nuestro Consejo. Dada en Madrid, a veynte y tres días del mes de agosto año del Señor de mill y quinientos y sesenta $y$ nueve.- (Siguen seis firmas).- Yo, Francisco de Vallejo, secretario de cámara de su cathólica magestad, la fize escriuir por su mandado con acuerdo de los del su Consejo.- Al pie: Licençia a la çiudad de Billena para que los vezinos della y su tierra y jurisdiçión puedan tener y tirar con arcabuzes, con que no sea con perdigones y guardando los meses de la cría y leies de vuestra alteza. 
1609 - 24 de septiembre - Villena

Libro de Actas.- Prevenciones del Concejo contra un posible ataque de los moros valencianos.

Primeramente dijeron que todo el reino de Valencia está muy alterado y se van pertrechando de armas y cercas, llevando a los lugares fuertes las mujeres y niños de los que no lo son, y la razón según dicen tienen es porque se dice que Su Majestad manda embarcar los moriscos del reino de Valencia, como se ha entendido del señor de Busot por una carta que ha escrito, y se echa de ver porque en Alicante está una escuadra de galeras y otra de galeones, y cada día llegan nuevas que desembarcan soldados para efectuarlo, y con esto están todos los lugares de los moriscos y lugares de cristianos viejos muy alborotados. $Y$ porque a tres o cuatro leguas de esta ciudad hay lugares de moriscos, como son Elda, Petrel, Monóvar, Novelda, Aspe, Crevillente, Elche y otros lugares, y si éstos huyesen de la gente de guerra que está en la costa, es caso sin duda han de venir para esta ciudad, la cual está abierta y sin armas, y sería muy fácil entrarla y saquearla, porque el número de los moriscos son muchos. Deseando esta ciudad prevenir y acudir al reparo del daño que podían hacer, les parece se ordene lo siguiente:

Lo primero que se reparen los muros y cercas, cerrando los que estuvieren abiertos dejando solamente las puertas, y éstas se cerrarán y abrirán a sus horas con mucho cuidado, lo cual hagan los vecinos de esta ciudad por hacenderas, tomando cal donde la hallaren, y se traiga piedra para ello. Todo lo cual se comete a Ginés Gómez de Mergelina, regidor, al capitán Pedro Rodríguez de Navarra, Pedro Miño, mayor, y Juan Martínez de Erquiaga y Medina, a los cuales se les da comisión en forma para ello, y la cal que se tomare se pague de los propios de esta ciudad, y la piedra y agua sea por hacenderas como está dicho, y en todo se les encarga la brevedad.

Lo segundo, que se envíen por doscientos arcabuces de munición con algunos mosquetes, y se repartan a los vecinos para que cada uno pague lo que costare. Asimismo se traiga de Murcia seis arrobas de pólvora y diez arrobas de plomo, y se comete lo susodicho a los Sres. Cebrián Navarro, alcalde, Diego de Valera y Hernando Estevan de Palencia, regidores, a los cuales se les da comisión en forma.

Lo tercero, que en el entretanto que se provee lo contenido en el capítulo antes de éste, se ronde casa noche por esta ciudad con cuarenta hombres, poniendo sus postas en las partes que le pareciere al Sr. Alcalde - Regidor que ha de salir por cabeza de la ronda, y desde luego salgan los señores regidores por su antigüedad a asistir en la ronda, y que el tal regidor tenga cuidado con los ministros de justicia a apercibirles que han de hacer la dicha ronda. 
Lo cuarto, que esta ciudad tiene dos cajas de atambores rotas; que se lleven a Alicante y se truequen por otras o se adoben, y lo que se gaste sea por cuenta de propios.

Y porque las cosas están de manera que cada hora hay novedad, y si para ello se hubiese de juntar este Ayuntamiento, citándolos no viene a efecto, así desde luego se acuerdo que en cada un día, desde ocho a las nueve de mañana se junte este Ayuntamiento, en el cual se hallen todos los regidores que se pudieren haber, y aquí se trate lo que más convenga al servicio de Su Majestad y bien público de esta Ciudad.

Luego el señor Alcalde Mayor mandó se notifique a todos los oficiales de este Ayuntamiento asistan en esta Ciudad sin salir de ella de hoy en adelante, si no fuere con licencia de su merced, so pena de mil maravedís aplicados a gastos de la guerra, y que el mandador lo notifique y dé fe de ello.

\section{VII}

1609 - 20 de noviembre - Villena

Libro de Actas.- El Corregidor da cuenta de la carta de Su Majestad en que ordena prevenir a la gente de guerra por si fuera necesario acudir al cerco que tenía puesto a los moros el Tercio de Lombardía.

Vióse una carta en este Ayuntamiento, que escribe el señor don Gutierre Pantoja, Corregidor y Justicia Mayor de este Corregimiento, en que por ella avisa en cómo ha recibido una carta de Su Majestad en que le manda prevenga toda la gente de guerra que fuere posible de este Corregimiento con las armas y municiones necesarios para que estén a punto por si es necesario vayan a apretar a los moros que el ejército del Tercio de Lombardía tiene cercados, y que avise a las ciudades y villas de este partido para que lo prevengan, alistándose toda la gente práctica y animosa con los arcabuces y escopetas, y que se haga para ello alarde para salir a servir a la orden que dieren los señores el Visorrey de Valencia o don Juan de Córdoba, Maese de Campo del Tercio de Lombardía, y otras cosas que la carta dice y él ha traído. Conferido sobre ello, dijeron que mañana sábado, que es fiesta de Nuestra Señora, se haga alarde y muestra general en esta ciudad para que salgan a él todas las personas desde diez y ocho a cincuenta años, con sus armas, y para ello asimismo se apregone que nadie salga de esta ciudad de la dicha ciudad. $Y$ hecho el dicho alarde, se acuerda que vaya por esta ciudad el señor Hernando de Medina, regidor, a dar razón al señor Corregidor el estado de lo que se vaya haciendo en virtud de la dicha carta. Que se despache el correo que ha traído la carta y se le paguen los ocho reales que el señor Corregidor manda de su viaje, de propios. Se diputaron a los señores Diego de Valera y Francisco Miño para que despachen al señor Hernando de Medina. 


\section{VIII}

1614 - 23 de agosto - Villena

Libro de Actas.- El Corregidor comunica que el Rey ha dado por acabada la expulsión de los moriscos.

Don Antonio Alvarez de Bohórquez Girón, caballero del hábito de Santiago, gentilhombre de la casa real, alguacil mayor del Santo Oficio de la Inquisición de la ciudad y reino de Granada, Veinticuatro de Córdoba, regidor perpetuo de Salamanca, señor de las villas de Veas, Espino y Lagunas Rubias, Cortes, Caparacena y Escoznar, regidor y justicia mayor de las ciudades de Chinchilla y Villena y nueve villas de su Corregimiento, conde de Utiel y Requena por el Rey nuestro señor, hago saber a el Concejo, Justicia y Regimiento de la ciudad de Villena y a las demás sus Justicias de la dicha ciudad, cómo yo he recibido una carta del Real Consejo que es del tenor siguiente:

Su Majestad ha sido servido que se dé por acabada la expulsión de los moriscos y que se mande a las Justicias de estos reinos y señoríos que no admitan de aquí adelante delación alguna ni causa nueva de moriscos, sino tan solamente contra aquéllos que habiendo sido expelidos se hubieren vuelto o volvieren, procediendo a la averiguación y castigo con gran cuidado y diligencia, haciendo particular pesquisa cada justicia en su jurisdicción si algún morisco se ha vuelto, y contra los que se probase semejante delito, si fuere de edad para servir en galeras, se le condene a ellas, $y$ siendo mujer o hombre viejo o impedido para servir en ellas, les sean dados doscientos azotes y sus bienes confiscados para la Cámara de su Majestad, y vuelvan a ser expelidos, así ellos como los que fueren condenados a galeras en cumpliendo el tiempo que en ellas han de servir; y si después de haber sido castigados $y$ vueltos a expeler tornasen a estos reinos y señoríos, tengan pena de muerte y confiscación de bienes, que se ejecute en ellos irremisiblemente. $Y$ los que hasta ahora estuvieren condenados en justicia $y$ acabadas las causas, para que salgan han de ser cumplidos con efecto, lo mismo los que fueren notorios moriscos y alistados por tales, cuyos padres y hermanos hayan salido y ellos no lo hayan hecho por haberse ocultado. Y porque la ejecución de esto consiste en que se cumpla lo susodicho con toda puntualidad, se os avisa de ello para que así lo hagáis sin que en ello haya omisión ni descuido, y si lo tuviéredes, se os hará cargo de ello en la residencia y seréis castigado con rigor. $Y$ en las cosas que se os ofrecieren dar cuenta, queda por Superintendente el Conde de Salazar, con el cual tendréis correspondencia y guardaréis lo que os advirtiere, que por haber entendido en la dicha expulsión está enterado en las cosas de ella. Y pondréis esta orden en los libros del Ayuntamiento para que sea notorio $y$ venga también a noticia de los que os sucedieren en este oficio. $Y$ asimismo enviaréis traslado de esta orden a la justicia de los lugares de señorío y abadengo de ese Partido, a los cuales se les advierta que si no atendieren con puntualidad y cuidado a la ejecución de la orden, serán castigados con mucha demostración. 
De Madrid, a cinco de agosto de mil seiscientos catorce años. Por mandado de los señores del Consejo; Yo, Juan Gallo de Andrada.

$Y$ porque conviene que lo suso dicho se guarde y se ejecute, luego que reciban ésta, harán las diligencias contenidas en esta carta del Consejo de Su Majestad, y si hubiere algunas personas que por la contravención de estos bandos merezcan ser castigados, les prenderán y averiguarán sus causas y me las remitirán para que provea justicia, y un traslado de todo ello se ponga en el libro capitular del Cabildo de esa ciudad, y traerá testimonio de ello y del recibo el portador, al cual mandarán pagar diez y seis reales de gastos de justicia, y no los habiendo, de Propios del Concejo sin le detener, y si le detuvieren por la paga, le mandarán pagar ocho reales cada día de los que le detuvieren en el dicho despacho.

Hecho en Yecla, en veinticinco días del mes de agosto de mil seiscientos catorce años.- Don Alonso Alvarez de Bohórquez.- Por su mandado, Francisco Tárrega.

Notificóse este mandamiento y carta a la justicia de esta ciudad en dos de septiembre de mil seiscientos catorce años, y en este día se sacó el traslado que concuerda con su original, de que doy fe.- Juan Alonso de Medina.

\section{IX}

1624 - 2 de diciembre - Villena

Libro de Actas.- Discusión sobre la solicitud de Elda de reducir el censo que paga por el agua de la Fuente del Chopo que se firmó cuando había aljama de moriscos en aquella villa.

Primeramente pidió licençia en este Cabildo don Jerónimo Fernández en nonbre del Conde de Elda para entrar a dar una enbajada por parte del Conde y uilla. Auiéndosele dado, entró y propuso de cómo la dicha billa responde en cada un año ochenta ducados de çenso por el agua de la Fuente el Chopo, questá en el término desta çiudad, y atento su Majestad a mandado reducir los censos, pretende la uilla se a de reduçir la dicha cantidad a razón de veinte uno, demás de lo qual paga a esta çiudad quatrocientos reales por los quarenta días del agua que esta ciudad reservó. Auiéndolo entendido y salido del Ayuntamiento, la dicha ciudad trató sobre ello, y el capitán Pedro Rodríguez de Nauarra dijo, visto el contrato entre esta ciudad y la uilla de Elda con D. Juan Coloma Calvillo, señor de ella, le parece que, auiendo sido contrato con aljama de moriscos de la dicha uilla de Elda, habiendo faltado los moriscos y aljama, y por la espulsión de ellos, auerse deshecho con su espulsión los contratos por ellos hechos, este contrato ansimismo tendrá poca fuerza, además que la villa dElda a muchos años que no lleva la dicha agua ni pareçe que la a menester pues no la lleua, y ansimismo todos los contratos de censo perpetuos y añales están reducidos a veinte el millar, que aunque este censo no tiene precio 
señalado, para el principal dél se a de entender a cómo se cargaron en aquel tienpo los censos perpetuos y a el quitar. Demás de esto que la dicha uilla de Elda paga a esta ciudad quatroçientos reales en cada un año por los quarenta días que la dicha ciudad reservó en sí, según de la escritura parece. Conforme a lo qual le pareçe será bien questa ciudad tome nuevo asiento con la dicha villa de Elda y con el Conde con las mayores firmezas que pueda, de manera que esta ciudad no pierda de todo punto los treinta mil maravedís de una parte y los quatrocientos reales de otra. Este es su pareçer.

Diego de Valera Torienço dijo que su parecer es que se saque un tanto de las escripturas questa çiudad tiene contra la villa dElda, y junto con el pareçer del capitán Pedro Rodríguez de Nauarra, se remita a un letrado de ciençia y conciençia y dé su pareçer, y si la çiudad tubiere justiçia se defienda, y si no, se tome asiento con el Conde y vezinos, conservando la paz y correspondençia que a auido en este çiudad y villa.

El regidor Fernando Medina dijo questa çiudad lo consulte con un letrado de ciencia y conciencia, $y$ todos se conformaron con esto.

\section{$\mathbf{X}$}

1624 - 22 de diciembre - Villena

Libro de Actas.- Parecer del licenciado Ferrer, abogado de Murcia, sobre los censos que paga la villa de Elda.

Tratóse en este Ayuntamiento en cómo esta ciudad acordó se remitiese al licenciado Ferer, abogado de la ciudad de Murcia, la escriptura questa ciudad tiene contra la uilla de Elda, en raçón de los treinta mill reales que cada un año paga a esta çiudad y sobre pretender se a de reducir a raçón de beynte uno, conforme la nueva premática. $Y$ auiéndose remitido, el licenciado Ferer da su pareçer, ques del tenor siguiente: $E$ visto el contrato $\gamma$ la premática nueba de la redución de los censos y el que haze la uilla dElda no és propiamente censo redimible, y así no queda comprehendida en la premática y baja y redución de la dicha premática. En quanto a la sigunda duda, los nuebos bezinos tendrán obligación estar por el contratado respeto que goçan del agua respeto que dio la causa a ello, porque se obligaron sus antecesores, y ansí, no pagando se puede ejecutar la escriptura, y esto me pareçe y lo fundaré si fuere neçesario. El licenciado Juan Ferer.

\section{$\mathbf{X I}$}

Varias fechas - Villena

Libros de Actas.- Acuerdos del Concejo sobre el proceso al al- 
pargatero Juan Martínez y su familia y sobre el asunto de los sambenitos.

21 de septiembre de 1564. - «Ansy mismo por quanto a venido a notiçia de los dichos sennores de Ayuntamiento que por el Santo offiçio de Inquisiçion esta preso vn moço que se dize Juan Martinez, hijo de Juan Martinez, alpargatero, natural de Villanueba de Alcaraz, y se presume que es confeso, y esta çiudad tiene previllegio que los semajantes no pueden biuir en ella, por tanto mandan que se escriba vna carta a los muy rreberendos sennores Inquisidores que quando a sus merçedes pareçiere, para que esta çibdad pueda pedir testimonio de lo dicho, manden dar abiso para que esta çibdad pueda prover por virtud del privilegio lo que fuere justiçia conforme a dicho previllegio».

27 y 28 de enero de 1566. «Y ansimismo dixeron que por quanto los señores de Ayuntamiento deste anno proximo pasado fue mandado a los hijos de Juan Martinez; alpargatero, natural de Alcaraz e morador que fue en esta çibdad, depositasen dineros para hazer sus probanças e se hizieron, e por ellas paresçio los suso dichos no ser de casta de cristianos viejos, $y$ ansi se pronunçio sentençia por el qual les a sido mandado se alegen de esta çibdad e no se abezinen en ella, en conserbaçion del preuilegio conçedido por los Reyes Catolicos, y ansi mandaron executar la dicha sentençia, e a mi el presente escriuano se los notifique para que dentro de ocho dias primeros siguientes salgan de esta çibdad e de sus arrabales, e no lo faziendo, mandan dar su mandamiento al alguazil mayor de esta çibdad e a su lugarteniente para que los haga salir, lo qual ansi hagan cumplir so pena de çien mill maravedis aplicados a la camara de su Magestad, e ansy lo proveyeron e mandaron por que cumple a serviçio de Dios e de su Magestad en la observaçion del dicho previllegio y merçed que tiene esta çibdad.» "E despues de lo suso dicho, en la dicha çibdad de Villena, veintiocho dias del mes de Henero de mill e quinientos sesenta y seis años, por mi dicho escriuano fue notificado lo proveido en el ayuntamiento de suso contenido, a Jusepa e Anna Martinez, hijas de el dicho Juan Martinez, alpargatero, e a la dicha Mari Diaz, syendo presentes por testigos Juan Estevan, clerigo, e Martin Rodriguez, vezinos de la dicha çindad de Villena, los quales dixeron que piden treslado. Testigos, los dichos.

10 febrero de 1566. - «E ansi mismo acordaron que vaya el señor Geronimo Ball, regidor, a la villa de Almansa a comunicar e tomar pareçer qué deve hazer el dicho Ayuntamiento sobre el negoçio de los hijos de Mari Diaz e Juan Martinez, e sobrello qué se deve proveer en rrepuesta de la carta del Santo Offiçio de Ynquisiçion que a inbiado al dicho Ayuntamiento, e mandan se escriba carta de crehençia al dicho bachiller.

17 de febrero de 1566. - «Primeramente el señor Geronimo Ball, regidor, dio vna carta que truxo del señor bachiller Marzilla para los dichos señores de Ayuntamiento sobre el negoçio de los hijos de Mari Diaz y las escrituras que llevo, y hizo rrelaçion, por parte del dicho bachiller Marzilla, para que vaya vna persona del dicho Ayuntamiento a hazer rrelaçion a los magmificos sennores del Santo Offiçio de Ynquisicion de los negoçios de 
esta çibdad e de lo que pasa sobre ello para que a sus merçedes conste de la verdad, por quanto por la carta pareçe que no les a sido fecha çierta rrelaçion. $Y$ ansi mismo mandaron librar al señor Geronimo Balle, regidor, diez e seys rreales por dos dias que se a ocupado en la yda e buelta a hablar al dicho señor bacjiller Marzilla a la villa de Almansa sobre los dichos negoçios de los confesos y vn rreal por que lo dio a vn escribiente que escribio el pareçer e carta de el dicho bachiller Marzilla, que por todo fueron diez y siete rreales, los quales se libraron en Juan Estevan, mayordomo. (...) Ansymismo acordaron que se escriua a la villa de Almansa y villas de Yecla e Sax que se junten en la Casa de Nuestra Sennora de las Virtudes y por parte dellos vayan persona o personas de estos pueblos a ynformar a su magestad de las bexaçiones que padeçen y que castigue a los culpados, y a los que bien biuen, les conserbe con los preuillegios concedidos y que los pueblos rrespondan para quedar quando les parezca que se junten». " $Y$ para ynformaçion de los señores Ynquisidores, segun que arriba esta acordado, acordaron e mandaron que vaya el sennor Geronimo Balle, rregidor, a la çibdad de Murçia, al que mandan que se le entreguen las escrituras con la provança de la genelogia del dicho Juan Martinez, e con el pareçer del dicho liçençiado Lorca.»

2 de julio de 1566.- Primeramente otorgaron poder complido a Alonso Diaz, rreçebtor de su Magestad en Murcia, e a Gines Sanchez, para que pidan ante los mui magnificos sennores rreuerendos sennores Ynquisidores que el sennal de Sanbenito que por la penitençia que se dio a Juan Martinez, vezino de Villanueva de Alcaraz que quieren mandar enbiar a esta çibdad por bibir en ella su madre se an servido de lo mandar enbyar al lugar de Villanueva de Alcaraz donde es la parentela e naturaleza del dicho Juan Martinez, e sobrello hagan los dos juntos e cada vno ynsolidum los abtos e diligençias neçesarias, siendo presentes por testigos Cristoval Gasque e Juan Calderon e Beltran Serrano, vezinos de la dicha çiudad. E ansimismo, sobre lo suso dicho, mandaron escrevir a los dichos sennores Ynquisidores que sean servidos de mandar enbiar el dicho Sanbenito a Villanueva de Alcaraz donde es la genelogia del dicho Juan Martinez y no a esta çiudad, $y$ ansimismo mandar escribir a los dichos Alonso Diaz y Pero Sancho.

27 enero 1567. - Primeramente acordaron e mandaron que se escriua e rresponda a los sennores del Santo Offiçio de Ynquisiçion en rrespuesta de la carta que an an enbiado a los dichos señores de conçejo sobre lo tocante a los hijos de Juan Martinez, alpargatero $y$ que en ella se de rrazon como lo que se a hecho e hazen a ynstançia de vezinos desta çibdad que piden contra otros muchos vezinos de esta çiudad que no puedan ser vezinos desta çiudad sy no nostraren e provasen como no son de casta de judios ni confesos, que commo syenpre se a hecho se guarde el previllegio desta çiudad que sobrello tiene confirmado de su magestad, e que sobre esto se hazen las diligençias contra los hijos del dicho Juan Martinez, e no por que alguno dellos aya sido penitençiado por el Santo Offiçio, y para que sus merçedes sean bien ynformados de lo suso dicho, mandan que se 
escriva a Françisco Rodriguez Nauarro de la çiudad de Murçia e vezino de esta çiudad que le de la carta e ynforme de los negoçios e saque escritura para que sus merçedes dexen a esta çiudad hazer las cosas que le cunplen a su preuillegio. $Y$ mandan a mi, dicho escriuano, que escriba las cartas sobre ello e de la ynformaçion que se hizo sobre la genelogia del dicho Juan Martinez, alpargatero e sus hijos.

18 de septiembre de 1580.- Ansimismo se acordo que atento que en esta çibdad por la Santa Ynquisiçion an sido puestos treçe sanbenitos en la yglesia del sennor Santiago desta çibdat en quinze dias del mes de setiembre deste dicho año de mill y quinietos y ochenta, y por quanto esta çibdad tiene privilegios de los Reyes Catolicos confirmados por sus Magestades los Reyes suçesores y de su Magestad del Rey don Felipe nuestro señor que al presente rreyna, de que ningun confeso ni que tenga rraza de judio pueda biuir en esta çibdad ni abezindarse en ella, y los sanbenitos puestos son de personas que delinquieron antes de los dichos previllegios $y$ antes que ouiese Ynquisiçion en España y aquellos fueron echados desta çibdad muertos en ella por los cristianos viejos, como de las escrituras de perdon $y$ previlegios consta, y pues sus magestades hizieron merçed a la çibdad en aquel tienpo de escluillos de la dicha çibdad, entiendese que tanbien la hiziera de que no se les pusieran los sanbenitos, e porque la çibdad a hecho mucho sentimiento y los vezinos della quexandose de que no abiendo ningun dezendiente ni trasbersal ni debdo de ninguna manera de aquellos, algunas personas que podrian temer en la dicha çibdad el mismo nonbre se le podia seguir alguna nota de ynfamia y otras cosas que por la justificacion $y$ decoro del Santo Offiçio es bien que se digan y suplique al rreal Consejo de la Ynquisiçion Suprema y no se espresen aqui, acordaron que a este negoçio se ynbie a la Corte una persona que rrepresente a aquellos señores estas y otras cabsas conforme a lo que el señor liçençiado Antonio de Mergelina tiene aconsejado sobre esto a la çibdad y conforme a lo que los letrados della en la Corte ordenaren trate este negoçio con el calor y diligençia y negoçiaçion que la calidad del negoçio rrequiere para que los dichos sanbenitos se quiten del lugar donde estan puestos, y que para esto lleven el pareçer y ynstruçion del señor liçençiado Antonio de Mergelina para que lo consulten con el y con los letrados que la çibdad tiene en la dicha Cortes. (Se nombra a Pedro Rodríguez Navarro para que se encargue en la Corte de las confirmaciones de los privilegios que aún no están sentados en los libros de lo salvado).

29 de marzo de 1581.- «Primeramente se acuerda que se escriba a los señores Ynquisidores de Murçia vna carta de crédito para el señor Francisco Rodriguez Navarro sonre la confirmaçion que an de hazer sobre los sanbenitos que en esta çibdad se an puesto, y ansi mismo se escriva al señor Françisco Rodriguez para que haga merçed a esta çibdad de encargarse del dicho negoçio».

25 de noviembre de 1619.- «Acordose se de poder a Gaspar Cotes, familiar del Santo Oficio, para el negocio de los sanbenitos y que escriva en nombre de esta çibdad el dicho señor Alcalde, doctor Domene, $y$ ansi 
mismo se le de poder a el señor Hernando Estevan para la Inquisiçion de Quenca».

26 de julio de 1659. - «El tribunal de la Inquisiçion manda unos sanbenitos contra unos portugueses para que se fijen en la iglesia mayor. La ciudad protesto porque no hay ningun judio $\gamma$ que se suspenda la ceremonia por la nobleza de esta ciudad y la limpieza de sangre de que gozan sus vecinos». 